OPEN ACCESS

Edited by:

Ciriaco A. Piccirillo,

McGill University, Canada

Reviewed by:

Carlo Chizzolini,

Université de Genève, Switzerland

Florencia Rosetti,

Instituto Nacional de Ciencias Médicas y Nutrición Salvador Zubirán (INCMNSZ), Mexico

${ }^{*}$ Correspondence:

Xuyu Zhou

zhouxy@im.ac.cn

Specialty section:

This article was submitted to

Autoimmune and

Autoinflammatory Disorders,

a section of the journal

Frontiers in Immunology

Received: 01 February 2021

Accepted: 18 March 2021

Published: 09 April 2021

Citation:

Wei X, Zhang J and Zhou X (2021)

Ex-TFRs: A Missing Piece

of the SLE PUzzle?

Front. Immunol. 12:662305.

doi: 10.3389/fimmu.2021.662305

\section{Ex-TFRs: A Missing Piece of the SLE Puzzle?}

\author{
Xundong Wei ${ }^{1,2}$, Jianhua Zhang ${ }^{2,3}$ and Xuyu Zhou ${ }^{2,3 *}$ \\ ${ }^{1}$ Center of Biotherapy, Beijing Hospital, National Center of Gerontology, Institute of Geriatric Medicine, Chinese Academy of \\ Medical Sciences, Beijing, China, ${ }^{2}$ Savaid Medical School, University of Chinese Academy of Sciences, Beijing, China, ${ }^{3}$ CAS \\ Key Laboratory of Pathogenic Microbiology and Immunology, Institute of Microbiology, Chinese Academy of Sciences (CAS), \\ Beijing, China
}

Systemic lupus erythematosus (SLE) is a chronic multi-organ autoimmune disease involving the production of a wide range of autoantibodies and complement activation. The production of these high-affinity autoantibodies requires $T$ cell/B cell collaboration as well as germinal center (GC) formation. T follicular regulatory cells (TFRs) are functional specialized $T$ regulatory cells (Tregs) that safeguard against both self-reactive $T$ and $B$ cells. However, recent evidence suggests that TFRs are not always stable and can lose Foxp3 expression to become pathogenic "ex-TFRs" that gain potent effector functions. In this review, we summarize the literature on intrinsic and extrinsic mechanisms of regulation of TFR stability and discuss the potential role of TFR reprogramming in autoantibody production and SLE pathogenesis.

Keywords: systemic lupus erythematosus, T regulatory cell, ex-TFRs, Foxp3, stability, autoantibodies

\section{INTRODUCTION}

Systemic lupus erythematosus (SLE) is a chronic multi-organ autoimmune disease with wide clinical heterogeneity. The disease can cause injury to many organs, especially the kidneys, joints, and skin. The pathogenesis of SLE is not fully understood, but increased high-affinity self-antibody production and dysregulated immune tolerance have been implicated in the progression of the disease $(1,2)$. SLE often starts in late childhood or adolescence and predominantly affects females in their reproductive years, with a female/male ratio of 9:1; the reasons for this skewed sex ratio remain unclear $(3,4)$. In the 1950 s, only $50 \%$ of SLE patients survived for 5 years; now, due to early diagnosis and better treatment, most patients survive for more than 10 years. There is no effective treatment for SLE, and only a few drugs have been approved in the past 60 years, emphasizing the need for a better understanding of its pathogenesis.

A hallmark of SLE is the production of a wide range of autoantibodies by self-reactive B cells. Anti-nuclear antibodies (ANAs) are detected in $>95 \%$ of SLE patients, and subsequent deposition of immune complexes in endogenous tissue results in severe tissue damage and induction of inflammation $(5,6)$. The autoantibodies from lupus patients are high affinity, somatic mutated, and class switched, and their generation requires the formation of germinal centers (GCs) with assistance from follicular helper $\mathrm{T}$ cells (TFHs) (7). In addition to their involvement in GC formation, TFHs, a unique $\mathrm{CD} 4^{+}$subset of T cells with high expression of Bcl6, PD-1, and CXCR5, 
play a major role in the selection of high-affinity B cells. TFHs have thus emerged as a critical immunoregulator of antibody production as well as the pathogenesis of human SLE (8).

Another small population of $\mathrm{CD}^{+} \mathrm{T}$ cells, regulatory $\mathrm{T}$ cells (Tregs), maintain self-tolerance by suppressing both autoreactive $\mathrm{T}$ and $\mathrm{B}$ lymphocytes through the production of inhibitory cytokines such as IL-10, TGF- $\beta$, and IL-35 $(9,10)$. Similar to conventional T cells, TCR and MHC and peptide engagement will lead to the activation of Tregs and which contribute to the further development of functional specialized $\mathrm{T}$ follicular regulatory cells (TFRs). TFRs also express both Bcl6 and CXCR5 and are capable of traveling to B cell follicles to serve as gatekeepers controlling autoantibody production (11-13). Tregs were initially considered a stable lineage, but emerging evidence suggests that even fully committed Treg cells can lose their identity and be reprogrammed to effector T cells (14-17). Interestingly, reprogramming of Tregs has been observed in the follicular region. TFRs can lose their Foxp3 expression and become pathogenic "ex-TFRs" (18). Whether the autoreactive potential of ex-TFRs contributes to autoimmune disease is not known. In this review, we summarize recent progress in understanding the roles of signaling pathways and transcriptional and epigenetic regulation in modulating Treg and TFR stability. We also discuss the possibility that pathogenic ex-TFRs contribute to autoantibody production and the pathogenesis of SLE.

\section{TFRS}

In 1995, Sakaguchi et al. identified a small subset of CD4 ${ }^{+} \mathrm{T}$ cells that express the high-affinity IL-2 receptor IL-2R $\alpha$ (CD25) and are capable of suppressing autoimmunity upon transfer $(19,20)$. Indeed, mice lacking either IL-2R $\alpha$ or IL-2 develop severe systemic autoimmunity (21-23). The cells identified by Sakaguchi et al. are now known as Tregs, and in 2003, the transcription factor Forkhead Box P3 (Foxp3) was identified as the lineage-defining regulator of Tregs (24-26). The importance of Foxp3 has been illustrated by studies of Foxp3 gene mutations, immune dysregulation, polyendocrinopathy, enteropathy, and X-linked (IPEX) syndrome in humans, and Scurfy mutant mice bearing Foxp3 mutations develop lethal multi-organ autoimmunity (2730). In addition, ablation of Foxp3 in mature Tregs or depletion of Foxp $3^{+}$cells completely eliminates the suppressive capacity of Tregs and programs Tregs into pathogenic T cells (31).

Tregs are not a homogenous population. Depending on their developmental origin, Tregs can be divided into thymic Tregs (tTregs) and peripheral Tregs (pTregs) $(32,33)$. tTregs are induced in the thymus and are characterized by high-affinity self-antigen engagement (34). By contrast, pTregs are generated from conventional $\mathrm{CD} 4^{+} \mathrm{T}$ cells under conditions of high levels of transforming growth factor $\beta$ (TGF- $\beta$ ) and retinoic acid in the environment or in response to metabolites produced by microbiota in the gut (35). Although the TCR repertoires of pTregs and tTregs overlap, tTregs mainly recognize self-antigens, whereas pTregs also express TCRs specific for non-self- infectious antigens or innocuous commensal microbiota derived antigens; these latter TCRs are important for the maintenance of mucosal tolerance $(36,37)$.

Similar to conventional T cells, Treg TCR engagement is the first step in generating heterogeneous effector Tregs, which are functionally potent and capable of migrating to local tissue (38). Effector Tregs can differentiate into specialized subsets by adapting the same set of transcription factors that control the differentiation of helper $\mathrm{CD}^{+} \mathrm{T}$ cells. For example, the Th1 transcription factor T-bet drives the expression of CXCR3 in Tregs, which is important for regulating some Th1-mediated autoimmune responses (39), and the ROR $\gamma t$-expressing Treg is involved in the regulation of Th17-mediated experimental autoimmune encephalomyelitis (EAE) and colitis (40-42).

Bcl6-expressing TFR cells (TFRs) are a particularly important subset of effector Tregs that express CXCR5 and migrate to B cell follicles and GCs (11). TFRs are capable of modulating B cell responses and, given their unique localization, appear to be major players in controlling autoantibody production (43-48). Indeed, Treg-specific ablation of Bcl6 results in substantial increases in multiple autoreactive antibodies, including antidsDNA $(49,50)$. Sage et al. demonstrated the importance of TFR in controlling the production of a panel of self-antibodies in an elegant TFR-DTR model established by crossing Foxp3-Cre mouse with a CXCR5 floxed stop DTR (diphtheria toxin receptor) strain $(12,51)$. In this model, only cells expressing both Foxp3 and CXCR5 (such as TFRs) express DTR on the cell surface, making them susceptible to deletion upon administration of diphtheria toxin (DT).

TFRs differentiate from natural Treg precursors through interaction with dendritic cells (DCs) and require different costimulatory activation signals at different stages of differentiation. Treg cells do not express CXCR5 in the T-cell zone and only start to upregulate CXCR5 when they migrate to the border region between the $\mathrm{T}$ and $\mathrm{B}$ cell zones. These cells are defined as pre-TFRs (52). The early differentiation of pre-TFRs requires CD28 and ICOS helper signals from DC cells and is independent of B cells. Although the initial stage of TFR differentiation does not rely on B cells, the stable mature TFR program requires $\mathrm{B}$ cell assistance. $\mathrm{B}$ cell-deficient mice exhibit a large decrease in mature TFRs in the lymph nodes (47). In follicles, CD25 and Blimp-1 expression are downregulated in CD25 ${ }^{+}$TFRs, leading to the acquisition of the CXCR5 ${ }^{\text {hi }}$ Bcl $6{ }^{\text {hi }}$ phenotype, which allows these CD25- TFRs to traffic into the GC (Table 1). Sage and colleagues demonstrated that TFRs prevent self-reactive B cells from being activated by TFHs, most likely via attenuated production of cytokines (such as IL-21 and IL-4) and/ or costimulatory signals $(53,54)$. TFRs also prevent GC formation caused by foreign antigens (vaccines, microorganisms) by inhibiting the metabolic flux of B cells and through CTLA-4mediated inhibition of B cells. TFRs may physically interrupt bidirectional costimulation and linked recognition during immunological synapses between TFHs and B cells (55). A specific subtype of TFHs, SOSTDC $1^{+}$TFHs, promote TFR cell differentiation by inhibiting the $\beta$-catenin pathway through the secreted protein SOSTDC1 (56). 
TABLE 1 | The markers for the identification of TFR and TFH.

\begin{tabular}{|c|c|c|c|c|c|c|c|c|c|c|c|}
\hline Subtype & Foxp3 & CD25 & Blimp-1 & CXCR5 & PD-1 & ICOS & Bcl6 & CD44 & CD62L & Location & Autoreactive \\
\hline Naive Treg & + & + & - & - & - & - & - & - & + & Extrafollicle & High \\
\hline Pre-TFR & ++ & ++ & + & + & + & + & $+/-$ & + & - & T-B border & High \\
\hline $\mathrm{CD}^{2} 5^{+} \mathrm{TFR}$ & ++ & ++ & ++ & ++ & ++ & ++ & ++ & + & - & Follicule & High \\
\hline CD25־TFR & ++ & - & - & +++ & +++ & +++ & +++ & + & - & GC & High \\
\hline Ex-TFR & - & - & - & +++ & +++ & +++ & +++ & + & - & $\mathrm{GC}$ & High \\
\hline Naive T & - & - & - & - & - & - & - & - & + & Extrafollicle & Low \\
\hline Pre-TFH & - & - & - & + & + & + & $+/-$ & + & - & T-B border & Low \\
\hline TFH & - & - & - & ++ & ++ & ++ & ++ & + & - & Follicule & Low \\
\hline GC-TFH & - & - & - & +++ & +++ & +++ & +++ & + & - & GC & Low \\
\hline
\end{tabular}

Defects in Treg function and/or number, particularly the TFR subset, are thought to contribute to SLE pathogenesis, but conflicting results have been reported. Some groups have found an increase in TFRs in SLE patients compared with healthy controls (57-59), whereas others have found reduced numbers or impaired function of circulating TFRs or Tregs in SLE patients $(60,61)$. Other groups have observed no abnormalities $(62,63)$. These discrepancies are due in part to the lack of a unique marker or combination of markers for identifying and isolating bona fide Tregs, the use of different in vitro stimuli, and the presence or absence of antigen-presenting cells (APCs) in ex vivo functional assays (64). An important challenge in the study of the pathogenesis of SLE is the difficulty of obtaining patient lymphoid tissues to assess TFRs directly; for this reason, most studies have focused on circulating Tregs in peripheral blood.

\section{FOXP3 STABILITY OF TFRS}

Tregs were initially considered a stable cell lineage committed to immunosuppressive function, but accumulating evidence indicates that they can lose Foxp3 expression and undergo reprogramming to other types of effector $\mathrm{T}$ cells. Upon transfer into $\mathrm{CD} 3 \mathrm{e} \mathrm{KO}$ mice, Foxp $3^{+} \mathrm{CD}^{+} \mathrm{T}$ cells terminate Foxp3 expression and differentiate into TFHs in Peyer's patches (14). $\mathrm{CD} 25^{-} \mathrm{Foxp} 3^{+} \mathrm{T}$ cells are likely more unstable than cells expressing CD25. In a fate-mapping experiment involving Foxp3 bacterial artificial chromosome (BAC) transgenic mice expressing GFP-Cre under the control of the Foxp3 promoter, we demonstrated that a fraction of Tregs are not stable. These "ex-Tregs", which no longer express Foxp3, have an activatedmemory $\mathrm{T}$ cell phenotype and the ability to produce inflammatory cytokines such as IFN- $\gamma$ and IL-17. Importantly, ex-Tregs bearing the BDC2.5 TCR induce autoimmune diabetes upon adoptive transfer (15). Autoimmune inflammation exacerbates the instability of Foxp3. By using MOG tetramer to identify antigen-specific Tregs, we further demonstrated that Tregs can be converted into pathogenic $\mathrm{T}$ helper cells in an EAE mouse model, suggesting a link between strong TCR signaling and Treg instability (16).

As a major TGF- $\beta$ sensor, conserved noncoding sequence 1 (CNS1) in Foxp3 is critical for the generation of induced pTregs but dispensable for tTreg development. Given the heterogeneity of Tregs, we further generated a delta CNS1 Foxp3 BAC transgenic mouse strain that only traces committed and stable tTregs (17). We found that resting or naïve tTregs are stable, but upon development to TFRs, these cells can lose Foxp3 stability and be reprogrammed into a $\mathrm{T}$ helper lineage (17).

Sage et al. recently confirmed that a population of TFRs can lose Foxp3 expression in experiments using inducible Foxp3 fatemapper mice (FoxP3 ${ }^{\text {ERT2-Cre }}$-Rosa26 Lox-Stop-Lox-TdTomato). In this model, Cre-ERT2 is limited to the cytoplasm in the absence of tamoxifen. Upon administration of tamoxifen, the tamoxifen metabolite 4-OHT (an analog of estrogen) binds to ERT, allowing Cre-ERT2 to enter the nucleus and exert Cre recombinase activity, thus triggering the expression of the fluorescent protein TdTomato in Foxp ${ }^{+}$Treg cells. In contrast to continuous labeling, inducible labeling of Foxp $3^{+}$Tregs with TdTomato during the immunization period avoids cell labeling due to transient Foxp3 expression and permits the assessment of bona fide Treg maintenance. Sage et al. immunized these mice with NP-OVA and $7 \mathrm{~d}$ later assessed the frequency of $\mathrm{CXCR}^{+} \mathrm{CD}^{+}{ }^{+} \mathrm{TdTomato}^{+} \mathrm{Foxp} 3^{\text {low }}$ "ex-TFR" populations. In this model, $\backsim 80 \%$ of $\mathrm{CD}^{+} \mathrm{CXCR}^{+}{ }^{+} \mathrm{TdTomato}^{+}$cells retained Foxp3 (TFRs); the remaining $\backsim 20 \%$ lost Foxp3 expression (ex-TFRs).

In summary, although TFRs are a functionally specialized subset of Tregs that selectively survey the autoreactive antibody response in the GC, continuous localization of TFRs in the GC might have a detrimental effect on Treg stability, leading to loss of Foxp3 expression and reprogramming to TFHs (Figure 1) (18).

\section{WHY DO TFRS PREFERENTIALLY LOSE FOXP3?}

The stability of Foxp3 expression is largely determined by the methylation status of the CNS2 region of the Foxp3 gene locus, which is also known as the Treg-specific demethylated region (TSDR) $(65,66)$. Foxp3 CNS2 contains $11 \mathrm{CpG}$ sites, which are all methylated in peripheral conventional $\mathrm{T}$ cells as well as thymic DP and CD4 SP cells. Gradual demethylation of CNS2 occurs during tTreg development $(67,68)$; this process is not passively cell cycle dependent but is mediated by Tet-dependent oxidation, which is primarily mediated by Tet2 and Tet3 (69). Demethylation of CNS2 leads to the recruitment of transcription 


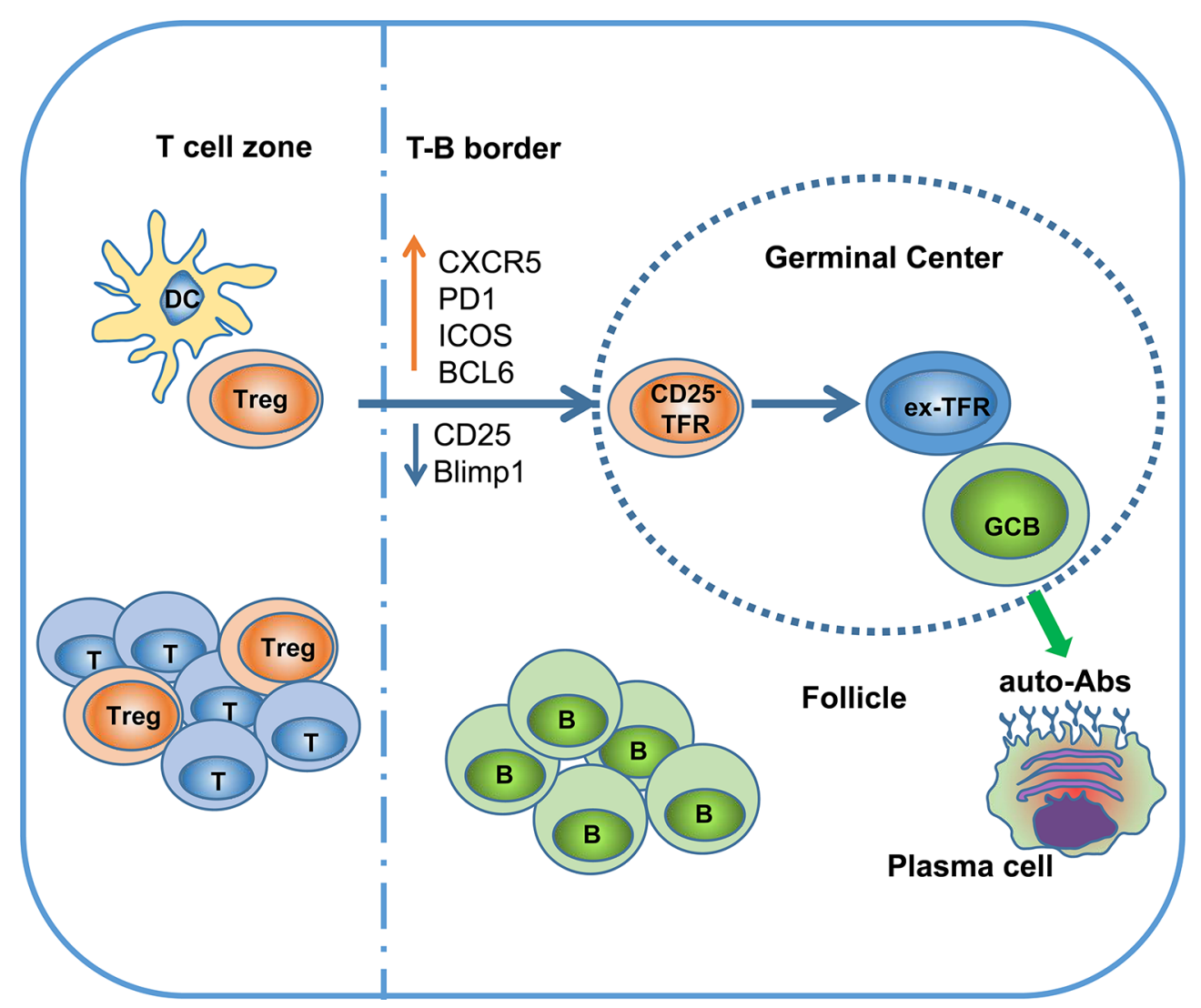

FIGURE 1 | Ex-TFRs: a missing piece of the SLE puzzle. Naïve Treg cells can interact with dendritic cells (DCs) to become activated and further migrate into the germinal center (GC) region through upregulation of CXCR5 and BCL6. In the follicle and GC, TFRs play an important role in regulating antigen (Ag)-specific TFHs and antibody-secreting cells. Since the GC is not favorable to stable Foxp3 expression, some TFRs will lose Foxp3 and develop into pathogenic TFHs (ex-TFRs). Ex-TFRs tend to recognize self-antigens, which may promote autoreactive humoral immunity.

factors such as Cbf $\beta$, Runx1, STAT5, and Foxp3 itself, thereby reinforcing Foxp3 expression on Tregs $(65,70-72)$. Indeed, genetically deleting either the CNS2 enhancer of the Foxp3 locus or Tet family proteins leads to a destabilized Treg lineage and the development of spontaneous autoimmunity and chronic inflammation (73).

Treg stability is influenced by many intrinsic and extrinsic factors, particularly cytokines and their downstream signaling pathways. IL-2 and STAT5 activation maintain Foxp3 stability by binding directly to CNS2, and the Hippo kinases Mst1 and Mst2 promote STAT5 activation to further strengthen the Treg lineage $(74,75)$. By contrast, IL- 4 and IL- 6 can have detrimental effects on the Treg lineage. IL-4 receptor (IL-4R) knock-in mice in which IL-4R signaling is specifically upregulated exhibit reduced Treg stability and promotion of the Th2 response (76). STAT6 and STAT3, which are downstream of IL-4R, appear to compete with STAT5 at the CNS2 region of Foxp3. Depletion of SOSC1 (Socs $1^{\mathrm{f} / \mathrm{fl}} \times$ Foxp $3^{\text {YFP-Cre }}$ mice), a natural inhibitor of STAT proteins, destabilizes the Treg lineage, and more interestingly, adoptive transfer of SOSC1-deficient Tregs is sufficient to induce autoimmune colitis (77).
Although ablation of TCR in mature Tregs has little impact on Treg stability, overstimulation of Tregs via dysregulation of TCR and/or co-stimulation profoundly destabilizes the Treg lineage. A number of negative regulators of the TCR signaling pathway, such as PTEN, ITCH, Vhl, and PTPN, play important roles in maintaining the stability of the Treg lineage (78-80). Interestingly, Tregs themselves are partially anergic compared with conventional $\mathrm{T}$ cells. Under conditions of homeostasis, Tregs remain anergic, but TCR signaling upon weak stimulation confers strong suppressive potential on Tregs without reducing the stability of the lineage $(81,82)$. However, overstimulation causes Treg destabilization and reprogramming into pathogenic effector cells $(17,80,83)$. The detailed molecular mechanism of the TCR signaling pathway has not been fully elucidated, but metabolic mechanisms could be very important; some metabolic pathways may interact with transcriptional and epigenetic regulation to modulate the Treg lineage.

Another important regulator of Treg lineage maintenance is the Foxp3 complex itself; roles of EzH2, RelA, and Runx, among other components of the complex, have been demonstrated (84, 85). Post-translational modification of the Foxp3 protein is part 
of a feedback loop that controls Foxp3 stability. CRISPR-Cas9based screening is beginning to reveal a more comprehensive picture of Treg lineage regulation, and new regulators such as Usp22, Rnf20, and Brd9 have been identified (86, 87). Interestingly, Zheng et al. found that non-canonical BAF (ncBAF) can localize at Foxp3 cis-regulatory elements to promote Foxp3 binding, whereas another SWI/SNF subunit, PBAF, seems to exert opposing effects (88).

In addition to its critical role in maintaining Foxp3 stability $(89,90)$, the IL-2/STAT5 signaling pathway is a potent negative regulator of TFH differentiation. IL-2 has been reported to repress TFR differentiation by a STAT5/Blimp-1 dependent mechanism (91). Thus, downregulation of the high-affinity IL-2 receptor CD25 is likely a common strategy for avoiding excessive STAT5 signaling in TFRs and TFHs. Consistent with this notion, CD25 expression is typically low or absent on TFHs and TFRs (92). By contrast, TFRs express high levels of inducible costimulator (ICOS), a co-stimulation molecule belonging to the CD28 family. ICOS signaling through the PI3K/AKT pathway is essential for the initiation of TFH and TFR differentiation and is also an important survival signal for CD25 effector Tregs (9395). However, as mentioned above, such positive signals can dampen Treg stability; for example, loss of Blimp-1, a strong transcriptional repressor of Bcl6, boosts TFR differentiation but has a detrimental effect on Treg stability (96). Together, the CD25 and ICOS signal switch during TFR cell differentiation is the driving force for programming TFRs to become TFHs (96).This notion is also consistent with previous adoptive transfer experiments showing that $\mathrm{CD} 25^{-} \mathrm{Foxp}^{+}$cells preferentially differentiate into effector TFHs under lymphopenic conditions (Table 1).

\section{EX-TFRS: A MISSING PIECE OF THE SLE PUZZLE?}

The functional role of ex-TFRs is not fully understood. The large majority of TFRs express Helios, a transcription factor expressed by tTregs (97), suggesting that TFRs are thymic in origin and biased toward self-antigens. This notion is further supported by recent studies indicating a highly diverse TCR repertoire of TFRs $(36,37)$. The loss of Foxp3 expression on TFRs generates a population of $\mathrm{T}$ cells with the potential to attack self-tissue. These cells could have a similar function as autoreactive TFHs. Sage et al. showed that exTFRs lose their suppressive function and have a transcriptional signature that is more similar to TFHs than TFRs (18). Moreover, multiple lines of Treg conditional knockout mice exhibit defects in maintenance of Treg stability, in association with an increased autoreactive humoral response and even the development of lupus-

\section{REFERENCES}

1. Yu C, Gershwin ME, Chang C. Diagnostic criteria for systemic lupus erythematosus: a critical review. J Autoimmun (2014) 48-49:10-3. doi: 10.1016/j.jaut.2014.01.004 like autoimmune disorders (98-100). For example, mice in which PTEN is conditionally knocked out in Tregs develop a lupus-like autoimmune lymphoproliferative disease characterized by excessive levels of TFHs and B cell activation. These mice also exhibit increased serum levels of multiple auto-antibodies and creatinine, indicating renal pathology $(80,101)$. Tet $2 / 3$ conditional knockout mice develop lethal autoimmunity in association with the production of numerous self-antibodies (73), and a similar autoimmune disease is observed in Foxp3Cre ${ }^{\mathrm{WT} / \mathrm{Cre}} \mathrm{Tet} 2 / 3^{\mathrm{fl} / \mathrm{fl}}$ heterozygous female mice, which harbor half of the wild type of Tregs in the same mice (73). These results strongly support the notion that ex-Tregs are self-recognition biased and have pathogenic potential (Figure 1).

Treg stability has not been directly tested in mouse models of lupus or human patients. However, Benoist et al. found that Foxp $3^{+}$Treg cells are unstable in NZW mice, which may explain the reduced sensitivity of this NZW Tregs to limiting doses of trophic cytokines, IL-2 and -33 (102). In addition, this instability may provide a genetic explanation for disease pathogenesis, as NZW $\times$ NZB F1 female mice develop a severe autoimmune disease that shares many features of SLE in human patients (103).

\section{CONCLUSIONS}

SLE is an autoimmune disease characterized by the production of a wide range of autoantibodies, and its exact pathoetiology remains elusive. Although TFRs play a critical role in controlling autoantibody production, the migration of TFRs to the follicular region and GC does not favor stable Foxp3 expression, and some TFRs even lose Foxp3 and develop into TFHs with pathogenic potential. These ex-TFRs are likely biased toward self-recognition and might promote autoreactive humoral immunity. A better understanding of the role of exTFRs could have important therapeutic implications for SLE and many other autoimmune diseases.

\section{AUTHOR CONTRIBUTIONS}

$\mathrm{XW}$, JZ, and XZ wrote the manuscript. All authors contributed to the article and approved the submitted version.

\section{FUNDING}

This work was supported by the National Natural Science Foundation of China (31870911, 81802872), the National Science and Technology Major Project of China (2016ZX10004222-007 and 2018ZX10301-208-002-002).

2. Mohan C, Putterman C. Genetics and pathogenesis of systemic lupus erythematosus and lupus nephritis. Nat Rev Nephrol (2015) 11:329-41. doi: 10.1038/nrneph.2015.33

3. Harry O, Yasin S, Brunner H. Childhood-Onset Systemic Lupus Erythematosus: A Review and Update. J Pediatr (2018) 196:22-30 e2. doi: 10.1016/j.jpeds.2018.01.045 
4. Feldman CH, Hiraki LT, Liu J, Fischer MA, Solomon DH, Alarcon GS, et al. Epidemiology and sociodemographics of systemic lupus erythematosus and lupus nephritis among US adults with Medicaid coverage, 2000-2004. Arthritis Rheumatol (2013) 65:753-63. doi: 10.1002/art.37795

5. Burbelo PD, Keller J, Kopp JB. New horizons for human pathogenic autoantibodies. Discovery Med (2015) 20:17-25.

6. Hamilton JA, Hsu HC, Mountz JD. Autoreactive B cells in SLE, villains or innocent bystanders? Immunol Rev (2019) 292:120-38. doi: 10.1111/ imr.12815

7. Jenks SA, Cashman KS, Woodruff MC, Lee FE, Sanz I. Extrafollicular responses in humans and SLE. Immunol Rev (2019) 288:136-48. doi: 10.1111/imr.12741

8. Blanco P, Ueno H, Schmitt N. T follicular helper (Tfh) cells in lupus: Activation and involvement in SLE pathogenesis. Eur J Immunol (2016) 46:281-90. doi: 10.1002/eji.201545760

9. Josefowicz SZ, Lu LF, Rudensky AY. Regulatory T cells: mechanisms of differentiation and function. Annu Rev Immunol (2012) 30:531-64. doi: 10.1146/annurev.immunol.25.022106.141623

10. Wei X, Zhang J, Gu Q, Huang M, Zhang W, Guo J, et al. Reciprocal Expression of IL-35 and IL-10 Defines Two Distinct Effector Treg Subsets that Are Required for Maintenance of Immune Tolerance. Cell Rep (2017) 21:1853-69. doi: 10.1016/j.celrep.2017.10.090

11. Wing JB, Kitagawa Y, Locci M, Hume H, Tay C, Morita T, et al. A distinct subpopulation of $\mathrm{CD} 25(-) \mathrm{T}$-follicular regulatory cells localizes in the germinal centers. Proc Natl Acad Sci USA (2017) 114:E6400-E09. doi: 10.1073/pnas.1705551114

12. Sage PT, Sharpe AH. The multifaceted functions of follicular regulatory $\mathrm{T}$ cells. Curr Opin Immunol (2020) 67:68-74. doi: 10.1016/j.coi.2020.10.009

13. Wing JB, Lim EL, Sakaguchi S. Control of foreign Ag-specific Ab responses by Treg and Tfr. Immunol Rev (2020) 296:104-19. doi: 10.1111/imr.12888

14. Tsuji M, Komatsu N, Kawamoto S, Suzuki K, Kanagawa O, Honjo T, et al. Preferential generation of follicular B helper T cells from Foxp $3+\mathrm{T}$ cells in gut Peyer's patches. Science (2009) 323:1488-92. doi: 10.1126/ science.1169152

15. Zhou X, Bailey-Bucktrout SL, Jeker LT, Penaranda C, Martinez-Llordella M, Ashby M, et al. Instability of the transcription factor Foxp3 leads to the generation of pathogenic memory T cells in vivo. Nat Immunol (2009) 10:1000-7. doi: 10.1038/ni.1774

16. Bailey-Bucktrout SL, Martinez-Llordella M, Zhou X, Anthony B, Rosenthal $\mathrm{W}$, Luche $\mathrm{H}$, et al. Self-antigen-driven activation induces instability of regulatory $\mathrm{T}$ cells during an inflammatory autoimmune response. Immunity (2013) 39:949-62. doi: 10.1016/j.immuni.2013.10.016

17. Zhang Z, Zhang W, Guo J, Gu Q, Zhu X, Zhou X. Activation and Functional Specialization of Regulatory $\mathrm{T}$ Cells Lead to the Generation of Foxp3 Instability. J Immunol (2017) 198:2612-25. doi: 10.4049/jimmunol.1601409

18. Hou S, Clement RL, Diallo A, Blazar BR, Rudensky AY, Sharpe AH, et al. FoxP3 and Ezh2 regulate Tfr cell suppressive function and transcriptional program. J Exp Med (2019) 216:605-20. doi: 10.1084/jem.20181134

19. Sakaguchi S, Sakaguchi N, Asano M, Itoh M, Toda M. Immunologic selftolerance maintained by activated $\mathrm{T}$ cells expressing IL-2 receptor alphachains (CD25). Breakdown of a single mechanism of self-tolerance causes various autoimmune diseases. J Immunol (1995) 155:1151-64.

20. Itoh M, Takahashi T, Sakaguchi N, Kuniyasu Y, Shimizu J, Otsuka F, et al. Thymus and autoimmunity: production of $\mathrm{CD} 25+\mathrm{CD} 4+$ naturally anergic and suppressive $\mathrm{T}$ cells as a key function of the thymus in maintaining immunologic self-tolerance. J Immunol (1999) 162:5317-26.

21. Furtado GC, Curotto de Lafaille MA, Kutchukhidze N, Lafaille JJ. Interleukin 2 signaling is required for $\mathrm{CD} 4(+)$ regulatory $\mathrm{T}$ cell function. J Exp Med (2002) 196:851-7. doi: 10.1084/jem.20020190

22. Nelson BH. Interleukin-2 signaling and the maintenance of self-tolerance. Curr Dir Autoimmun (2002) 5:92-112. doi: 10.1159/000060549

23. Mullins GN, Valentine KM, Al-Kuhlani M, Davini D, Jensen KDC, Hoyer KK. T cell signaling and Treg dysfunction correlate to disease kinetics in IL2Ralpha-KO autoimmune mice. Sci Rep (2020) 10:21994. doi: 10.1038/ s41598-020-78975-y

24. Fontenot JD, Gavin MA, Rudensky AY. Foxp3 programs the development and function of CD4+CD25+ regulatory T cells. Nat Immunol (2003) 4:3306. doi: $10.1038 /$ ni 904
25. Hori S, Nomura T, Sakaguchi S. Control of regulatory T cell development by the transcription factor Foxp3. Science (2003) 299:1057-61. doi: 10.1126/ science. 1079490

26. Khattri R, Cox T, Yasayko SA, Ramsdell F. An essential role for Scurfin in CD4+CD25+ T regulatory cells. Nat Immunol (2003) 4:337-42. doi: 10.1038/ni909

27. Bennett CL, Christie J, Ramsdell F, Brunkow ME, Ferguson PJ, Whitesell L, et al. The immune dysregulation, polyendocrinopathy, enteropathy, Xlinked syndrome (IPEX) is caused by mutations of FOXP3. Nat Genet (2001) 27:20-1. doi: 10.1038/83713

28. Bennett CL, Ochs HD. IPEX is a unique X-linked syndrome characterized by immune dysfunction, polyendocrinopathy, enteropathy, and a variety of autoimmune phenomena. Curr Opin Pediatr (2001) 13:533-8. doi: 10.1097/ 00008480-200112000-00007

29. Brunkow ME, Jeffery EW, Hjerrild KA, Paeper B, Clark LB, Yasayko SA, et al. Disruption of a new forkhead/winged-helix protein, scurfin, results in the fatal lymphoproliferative disorder of the scurfy mouse. Nat Genet (2001) 27:68-73. doi: $10.1038 / 83784$

30. Sawant DV, Vignali DA. Once a Treg, always a Treg? Immunol Rev (2014) 259:173-91. doi: 10.1111/imr.12173

31. Williams LM, Rudensky AY. Maintenance of the Foxp3-dependent developmental program in mature regulatory $\mathrm{T}$ cells requires continued expression of Foxp3. Nat Immunol (2007) 8:277-84. doi: 10.1038/ni1437

32. Bluestone JA, Abbas AK. Natural versus adaptive regulatory T cells. Nat Rev Immunol (2003) 3:253-7. doi: 10.1038/nri1032

33. Hori S. Lineage stability and phenotypic plasticity of Foxp3(+) regulatory $T$ cells. Immunol Rev (2014) 259:159-72. doi: 10.1111/imr.12175

34. Jordan MS, Boesteanu A, Reed AJ, Petrone AL, Holenbeck AE, Lerman MA, et al. Thymic selection of CD4+CD25+ regulatory T cells induced by an agonist self-peptide. Nat Immunol (2001) 2:301-6. doi: 10.1038/86302

35. Atarashi K, Tanoue T, Shima T, Imaoka A, Kuwahara T, Momose Y, et al. Induction of colonic regulatory $\mathrm{T}$ cells by indigenous Clostridium species. Science (2011) 331:337-41. doi: 10.1126/science.1198469

36. Maceiras AR, Almeida SCP, Mariotti-Ferrandiz E, Chaara W, Jebbawi F, Six $\mathrm{A}$, et al. $\mathrm{T}$ follicular helper and $\mathrm{T}$ follicular regulatory cells have different TCR specificity. Nat Commun (2017) 8:15067. doi: 10.1038/ncomms15067

37. Ritvo PG, Saadawi A, Barennes P, Quiniou V, Chaara W, El Soufi K, et al. High-resolution repertoire analysis reveals a major bystander activation of Tfh and Tfr cells. Proc Natl Acad Sci USA (2018) 115:9604-09. doi: 10.1073/ pnas. 1808594115

38. Li MO, Rudensky AY. T cell receptor signalling in the control of regulatory T cell differentiation and function. Nat Rev Immunol (2016) 16:220-33. doi: 10.1038/nri.2016.26

39. Koch MA, Thomas KR, Perdue NR, Smigiel KS, Srivastava S, Campbell DJ. T-bet(+) Treg cells undergo abortive Th1 cell differentiation due to impaired expression of IL-12 receptor beta2. Immunity (2012) 37:501-10. doi: 10.1016/j.immuni.2012.05.031

40. Ayyoub M, Deknuydt F, Raimbaud I, Dousset C, Leveque L, Bioley G, et al. Human memory FOXP3+ Tregs secrete IL-17 ex vivo and constitutively express the $\mathrm{T}(\mathrm{H}) 17$ lineage-specific transcription factor RORgamma t. Proc Natl Acad Sci USA (2009) 106:8635-40. doi: 10.1073/pnas.0900621106

41. Voo KS, Wang YH, Santori FR, Boggiano C, Wang YH, Arima K, et al. Identification of IL-17-producing FOXP3+ regulatory $\mathrm{T}$ cells in humans. Proc Natl Acad Sci USA (2009) 106:4793-8. doi: 10.1073/pnas.0900408106

42. Kim BS, Lu H, Ichiyama K, Chen X, Zhang YB, Mistry NA, et al. Generation of RORgammat(+) Antigen-Specific T Regulatory 17 Cells from Foxp3(+) Precursors in Autoimmunity. Cell Rep (2017) 21:195-207. doi: 10.1016/ j.celrep.2017.09.021

43. Sage PT, Sharpe AH. T follicular regulatory cells in the regulation of B cell responses. Trends Immunol (2015) 36:410-8. doi: 10.1016/j.it.2015.05.005

44. Sage PT, Sharpe AH. T follicular regulatory cells. Immunol Rev (2016) 271:246-59. doi: 10.1111/imr.12411

45. Maceiras AR, Fonseca VR, Agua-Doce A, Graca L. T follicular regulatory cells in mice and men. Immunology (2017) 152:25-35. doi: 10.1111/ imm. 12774

46. Chung Y, Tanaka S, Chu F, Nurieva RI, Martinez GJ, Rawal S, et al. Follicular regulatory $\mathrm{T}$ cells expressing Foxp3 and Bcl-6 suppress germinal center reactions. Nat Med (2011) 17:983-8. doi: 10.1038/nm.2426 
47. Linterman MA, Pierson W, Lee SK, Kallies A, Kawamoto S, Rayner TF, et al. Foxp3+ follicular regulatory $\mathrm{T}$ cells control the germinal center response. Nat Med (2011) 17:975-82. doi: 10.1038/nm.2425

48. Wollenberg I, Agua-Doce A, Hernandez A, Almeida C, Oliveira VG, Faro J, et al. Regulation of the germinal center reaction by Foxp3+ follicular regulatory T cells. J Immunol (2011) 187:4553-60. doi: 10.4049/jimmunol.1101328

49. Wu H, Chen Y, Liu H, Xu LL, Teuscher P, Wang S, et al. Follicular regulatory $\mathrm{T}$ cells repress cytokine production by follicular helper $\mathrm{T}$ cells and optimize IgG responses in mice. Eur J Immunol (2016) 46:1152-61. doi: 10.1002/ eji.201546094

50. Xie MM, Fang S, Chen Q, Liu H, Wan J, Dent AL. Follicular regulatory T cells inhibit the development of granzyme B-expressing follicular helper $\mathrm{T}$ cells. JCI Insight (2019) 4:e128076. doi: 10.1172/jci.insight.128076

51. Clement RL, Daccache J, Mohammed MT, Diallo A, Blazar BR, Kuchroo $\mathrm{VK}$, et al. Follicular regulatory $\mathrm{T}$ cells control humoral and allergic immunity by restraining early B cell responses. Nat Immunol (2019) 20:1360-71. doi: 10.1038/s41590-019-0472-4

52. Sayin I, Radtke AJ, Vella LA, Jin W, Wherry EJ, Buggert M, et al. Spatial distribution and function of $\mathrm{T}$ follicular regulatory cells in human lymph nodes. J Exp Med (2018) 215:1531-42. doi: 10.1084/jem.20171940

53. Sage PT, Alvarez D, Godec J, von Andrian UH, Sharpe AH. Circulating T follicular regulatory and helper cells have memory-like properties. J Clin Invest (2014) 124:5191-204. doi: 10.1172/JCI76861

54. Sage PT, Ron-Harel N, Juneja VR, Sen DR, Maleri S, Sungnak W, et al. Suppression by TFR cells leads to durable and selective inhibition of B cell effector function. Nat Immunol (2016) 17:1436-46. doi: 10.1038/ni.3578

55. Sage PT, Paterson AM, Lovitch SB, Sharpe AH. The coinhibitory receptor CTLA-4 controls B cell responses by modulating $\mathrm{T}$ follicular helper, $\mathrm{T}$ follicular regulatory, and T regulatory cells. Immunity (2014) 41:1026-39. doi: 10.1016/j.immuni.2014.12.005

56. Wu X, Wang Y, Huang R, Gai Q, Liu H, Shi M, et al. SOSTDC1-producing follicular helper $\mathrm{T}$ cells promote regulatory follicular $\mathrm{T}$ cell differentiation. Science (2020) 369:984-88. doi: 10.1126/science.aba6652

57. Xu B, Wang S, Zhou M, Huang Y, Fu R, Guo C, et al. The ratio of circulating follicular $\mathrm{T}$ helper cell to follicular $\mathrm{T}$ regulatory cell is correlated with disease activity in systemic lupus erythematosus. Clin Immunol (2017) 183:46-53. doi: 10.1016/j.clim.2017.07.004

58. Jacquemin C, Augusto JF, Scherlinger M, Gensous N, Forcade E, Douchet I, et al. OX40L/OX40 axis impairs follicular and natural Treg function in human SLE. JCI Insight (2018) 3:e122167. doi: 10.1172/jci.insight.122167

59. Liu C, Wang D, Song Y, Lu S, Zhao J, Wang H. Increased circulating CD4(+) CXCR5(+)FoxP3(+) follicular regulatory $\mathrm{T}$ cells correlated with severity of systemic lupus erythematosus patients. Int Immunopharmacol (2018) 56:261-68. doi: 10.1016/j.intimp.2018.01.038

60. Lyssuk EY, Torgashina AV, Soloviev SK, Nassonov EL, Bykovskaia SN. Reduced number and function of CD4+CD25highFoxP3+ regulatory T cells in patients with systemic lupus erythematosus. Adv Exp Med Biol (2007) 601:113-9. doi: 10.1007/978-0-387-72005-0_12

61. Valencia X, Yarboro C, Illei G, Lipsky PE. Deficient CD4+CD25high T regulatory cell function in patients with active systemic lupus erythematosus. J Immunol (2007) 178:2579-88. doi: 10.4049/jimmunol.178.4.2579

62. Alvarado-Sanchez B, Hernandez-Castro B, Portales-Perez D, Baranda L, Layseca-Espinosa E, Abud-Mendoza C, et al. Regulatory T cells in patients with systemic lupus erythematosus. J Autoimmun (2006) 27:110-8. doi: 10.1016/j.jaut.2006.06.005

63. Vargas-Rojas MI, Crispin JC, Richaud-Patin Y, Alcocer-Varela J. Quantitative and qualitative normal regulatory $\mathrm{T}$ cells are not capable of inducing suppression in SLE patients due to T-cell resistance. Lupus (2008) 17:289-94. doi: 10.1177/0961203307088307

64. Chavele KM, Ehrenstein MR. Regulatory T-cells in systemic lupus erythematosus and rheumatoid arthritis. FEBS Lett (2011) 585:3603-10. doi: 10.1016/j.febslet.2011.07.043

65. Zheng Y, Josefowicz S, Chaudhry A, Peng XP, Forbush K, Rudensky AY. Role of conserved non-coding DNA elements in the Foxp3 gene in regulatory T-cell fate. Nature (2010) 463:808-12. doi: 10.1038/nature08750

66. Li X, Liang Y, LeBlanc M, Benner C, Zheng Y. Function of a Foxp3 ciselement in protecting regulatory $\mathrm{T}$ cell identity. Cell (2014) 158:734-48. doi: 10.1016/j.cell.2014.07.030
67. Floess S, Freyer J, Siewert C, Baron U, Olek S, Polansky J, et al. Epigenetic control of the foxp3 locus in regulatory T cells. PloS Biol (2007) 5:e38. doi: 10.1371/journal.pbio.0050038

68. Ohkura N, Hamaguchi M, Morikawa H, Sugimura K, Tanaka A, Ito Y, et al. $\mathrm{T}$ cell receptor stimulation-induced epigenetic changes and Foxp3 expression are independent and complementary events required for Treg cell development. Immunity (2012) 37:785-99. doi: 10.1016/j.immuni.2012. 09.010

69. Yue X, Trifari S, Aijo T, Tsagaratou A, Pastor WA, Zepeda-Martinez JA, et al. Control of Foxp3 stability through modulation of TET activity. J Exp Med (2016) 213:377-97. doi: 10.1084/jem.20151438

70. Kim HP, Leonard WJ. CREB/ATF-dependent T cell receptor-induced FoxP3 gene expression: a role for DNA methylation. J Exp Med (2007) 204:154351. doi: 10.1084/jem.20070109

71. Rudra D, Egawa T, Chong MM, Treuting P, Littman DR, Rudensky AY. Runx-CBFbeta complexes control expression of the transcription factor Foxp3 in regulatory T cells. Nat Immunol (2009) 10:1170-7. doi: 10.1038/ ni.1795

72. Polansky JK, Schreiber L, Thelemann C, Ludwig L, Kruger M, Baumgrass R, et al. Methylation matters: binding of Ets-1 to the demethylated Foxp3 gene contributes to the stabilization of Foxp3 expression in regulatory $\mathrm{T}$ cells. J Mol Med (Berl) (2010) 88:1029-40. doi: 10.1007/s00109-010-0642-1

73. Yue X, Lio CJ, Samaniego-Castruita D, Li X, Rao A. Loss of TET2 and TET3 in regulatory $\mathrm{T}$ cells unleashes effector function. Nat Commun (2019) 10:2011. doi: 10.1038/s41467-019-09541-y

74. Shi H, Liu C, Tan H, Li Y, Nguyen TM, Dhungana Y, et al. Hippo Kinases Mst1 and Mst2 Sense and Amplify IL-2R-STAT5 Signaling in Regulatory T Cells to Establish Stable Regulatory Activity. Immunity (2018) 49:899-914 e6. doi: 10.1016/j.immuni.2018.10.010

75. Chen L. Non-canonical Hippo signaling regulates immune responses. $A d v$ Immunol (2019) 144:87-119. doi: 10.1016/bs.ai.2019.07.001

76. Pelly VS, Coomes SM, Kannan Y, Gialitakis M, Entwistle LJ, Perez-Lloret J, et al. Interleukin 4 promotes the development of ex-Foxp3 Th2 cells during immunity to intestinal helminths. J Exp Med (2017) 214:1809-26. doi: 10.1084/jem.20161104

77. Takahashi R, Nakatsukasa H, Shiozawa S, Yoshimura A. SOCS1 Is a Key Molecule That Prevents Regulatory T Cell Plasticity under Inflammatory Conditions. J Immunol (2017) 199:149-58. doi: 10.4049/jimmunol.1600441

78. Jin HS, Park Y, Elly C, Liu YC. Itch expression by Treg cells controls Th2 inflammatory responses. J Clin Invest (2013) 123:4923-34. doi: 10.1172/ JCI69355

79. Lee JH, Elly C, Park Y, Liu YC. E3 Ubiquitin Ligase VHL Regulates HypoxiaInducible Factor-1alpha to Maintain Regulatory $\mathrm{T}$ Cell Stability and Suppressive Capacity. Immunity (2015) 42:1062-74. doi: 10.1016/ j.immuni.2015.05.016

80. Shrestha S, Yang K, Guy C, Vogel P, Neale G, Chi H. Treg cells require the phosphatase PTEN to restrain TH1 and TFH cell responses. Nat Immunol (2015) 16:178-87. doi: 10.1038/ni.3076

81. Levine AG, Arvey A, Jin W, Rudensky AY. Continuous requirement for the TCR in regulatory T cell function. Nat Immunol (2014) 15:1070-8. doi: 10.1038/ni.3004

82. Vahl JC, Drees C, Heger K, Heink S, Fischer JC, Nedjic J, et al. Continuous T cell receptor signals maintain a functional regulatory $\mathrm{T}$ cell pool. Immunity (2014) 41:722-36. doi: 10.1016/j.immuni.2014.10.012

83. Huynh A, DuPage M, Priyadharshini B, Sage PT, Quiros J, Borges CM, et al. Control of PI(3) kinase in Treg cells maintains homeostasis and lineage stability. Nat Immunol (2015) 16:188-96. doi: 10.1038/ni.3077

84. DuPage M, Chopra G, Quiros J, Rosenthal WL, Morar MM, Holohan D, et al. The chromatin-modifying enzyme Ezh2 is critical for the maintenance of regulatory T cell identity after activation. Immunity (2015) 42:227-38. doi: 10.1016/j.immuni.2015.01.007

85. Samstein RM, Arvey A, Josefowicz SZ, Peng X, Reynolds A, Sandstrom R, et al. Foxp3 exploits a pre-existent enhancer landscape for regulatory T cell lineage specification. Cell (2012) 151:153-66. doi: 10.1016/j.cell. 2012.06.053

86. Cortez JT, Montauti E, Shifrut E, Gatchalian J, Zhang Y, Shaked O, et al. CRISPR screen in regulatory $\mathrm{T}$ cells reveals modulators of Foxp3. Nature (2020) 582:416-20. doi: 10.1038/s41586-020-2246-4 
87. Cameron J, Martino P, Nguyen L, Li X. Cutting Edge: CRISPR-Based Transcriptional Regulators Reveal Transcription-Dependent Establishment of Epigenetic Memory of Foxp3 in Regulatory T Cells. J Immunol (2020) 205:2953-58. doi: 10.4049/jimmunol.2000537

88. Loo CS, Gatchalian J, Liang Y, Leblanc M, Xie M, Ho J, et al. A Genome-wide CRISPR Screen Reveals a Role for the Non-canonical NucleosomeRemodeling BAF Complex in Foxp3 Expression and Regulatory T Cell Function. Immunity (2020) 53:143-57 e8. doi: 10.1016/j.immuni.2020.06.011

89. Fontenot JD, Rasmussen JP, Gavin MA, Rudensky AY. A function for interleukin 2 in Foxp3-expressing regulatory T cells. Nat Immunol (2005) 6:1142-51. doi: 10.1038/ni1263

90. Burchill MA, Yang J, Vogtenhuber C, Blazar BR, Farrar MA. IL-2 receptor beta-dependent STAT5 activation is required for the development of Foxp3+ regulatory T cells. J Immunol (2007) 178:280-90. doi: 10.4049/ jimmunol.178.1.280

91. Oestreich KJ, Mohn SE, Weinmann AS. Molecular mechanisms that control the expression and activity of Bcl-6 in TH1 cells to regulate flexibility with a TFH-like gene profile. Nat Immunol (2012) 13:405-11. doi: 10.1038/ni.2242

92. Botta D, Fuller MJ, Marquez-Lago TT, Bachus H, Bradley JE, Weinmann AS, et al. Dynamic regulation of $\mathrm{T}$ follicular regulatory cell responses by interleukin 2 during influenza infection. Nat Immunol (2017) 18:1249-60. doi: $10.1038 /$ ni.3837

93. Sage PT, Francisco LM, Carman CV, Sharpe AH. The receptor PD-1 controls follicular regulatory $\mathrm{T}$ cells in the lymph nodes and blood. Nat Immunol (2013) 14:152-61. doi: 10.1038/ni.2496

94. Leavenworth JW, Verbinnen B, Yin J, Huang H, Cantor H. A p85alphaosteopontin axis couples the receptor ICOS to sustained Bcl-6 expression by follicular helper and regulatory T cells. Nat Immunol (2015) 16:96-106. doi: 10.1038/ni.3050

95. Zhang R, Sage PT, Finn K, Huynh A, Blazar BR, Marangoni F, et al. B Cells Drive Autoimmunity in Mice with CD28-Deficient Regulatory T Cells. J Immunol (2017) 199:3972-80. doi: 10.4049/jimmunol.1700409

96. Shen E, Rabe H, Luo L, Wang L, Wang Q, Yin J, et al. Control of Germinal Center Localization and Lineage Stability of Follicular Regulatory T Cells by the Blimp1 Transcription Factor. Cell Rep (2019) 29:1848-61 e6. doi: 10.1016/j.celrep.2019.10.012
97. Sebastian M, Lopez-Ocasio M, Metidji A, Rieder SA, Shevach EM, Thornton AM. Helios Controls a Limited Subset of Regulatory T Cell Functions. J Immunol (2016) 196:144-55. doi: 10.4049/jimmunol.1501704

98. Zhou X, Jeker LT, Fife BT, Zhu S, Anderson MS, McManus MT, et al. Selective miRNA disruption in $\mathrm{T}$ reg cells leads to uncontrolled autoimmunity. J Exp Med (2008) 205:1983-91. doi: 10.1084/jem.20080707

99. Muto G, Kotani H, Kondo T, Morita R, Tsuruta S, Kobayashi T, et al. TRAF6 is essential for maintenance of regulatory $\mathrm{T}$ cells that suppress $\mathrm{Th} 2$ type autoimmunity. PloS One (2013) 8:e74639. doi: 10.1371/journal.pone.0074639

100. Liu B, Salgado OC, Singh S, Hippen KL, Maynard JC, Burlingame AL, et al. The lineage stability and suppressive program of regulatory $\mathrm{T}$ cells require protein $\mathrm{O}$ GlcNAcylation. Nat Commun (2019) 10:354. doi: 10.1038/s41467-019-08300-3

101. Wu D, Luo Y, Guo W, Niu Q, Xue T, Yang F, et al. Lkb1 maintains Treg cell lineage identity. Nat Commun (2017) 8:15876. doi: 10.1038/ncomms15876

102. Depis F, Kwon HK, Mathis D, Benoist C. Unstable FoxP3+ T regulatory cells in NZW mice. Proc Natl Acad Sci USA (2016) 113:1345-50. doi: 10.1073/ pnas. 1524660113

103. Elouaai F, Lule J, Benoist H, Appolinaire-Pilipenko S, Atanassov C, Muller S, et al. Autoimmunity to histones, ubiquitin, and ubiquitinated histone $\mathrm{H} 2 \mathrm{~A}$ in NZB x NZW and MRL-lpr/lpr mice. Anti-histone antibodies are concentrated in glomerular eluates of lupus mice. Nephrol Dial Transplant (1994) 9:362-6.

Conflict of Interest: XW consulted for Zhongke Qiyuan (Shenzhen) Biotechnology Co., Ltd. in T cell immunity.

The remaining authors declare that the research was conducted in the absence of any commercial or financial relationships that could be construed as a potential conflict of interest.

Copyright (c) 2021 Wei, Zhang and Zhou. This is an open-access article distributed under the terms of the Creative Commons Attribution License (CC BY). The use, distribution or reproduction in other forums is permitted, provided the original author(s) and the copyright owner(s) are credited and that the original publication in this journal is cited, in accordance with accepted academic practice. No use, distribution or reproduction is permitted which does not comply with these terms. 